\title{
Labral Tear in The Acetabulofemoral Joint in A Collegiate Female Athlete: A Case Study
}

\author{
Sydney M Baumgartner* \\ Department of Applied Medicine and Rehabilitation, USA
}

*Corresponding author: Sydney M Baumgartner, Department of Applied medicine and Rehabilitation, USA.

Received Date: September 14, 2019

Published Date: October 11, 2019

\begin{abstract}
This case investigates ongoing hip pain in a female collegiate beach volleyball athlete. The initial assessment, after thorough evaluation by the university's athletic training staff, was iliotibial band tightness with concern of a tear of the patient's acetabular labrum. The patient was religious to rehabilitation, performing it at least 3 times a week for 3 weeks, and was still having post-activity pain in her hip. The athletic trainers referred the patient to the team physician, who ordered a magnetic resonance arthrogram. Imaging revealed a tear in the patient's acetabular labrum which left her devastated. She had two bouts of mild depressive symptoms after the initial and final diagnosis. Each bout of symptoms was cleared up through a verbal conversation with the athletic training staff, that weighed the importance of volleyball in relation to having pain for the rest of the patient's life. The patient still held volleyball as a high priority and decided to have surgical repair of her acetabular labrum after her time allowance as a collegiate athlete had expired. Surgical intervention is the greatest treatment for an acetabular labral tear and should be performed as acutely as possible, in order to reduce additional damage to the cartilage of the joint capsule. This patient only had one symptom of a labral tear during the initial evaluation, but this pathology was kept in her differential diagnosis due to the inability to rule it out until a magnetic resonance arthrogram was performed. The signs of a mental illness shown by this patient were addressed early by the athletic training staff. The symptoms did not progress, nor did they ever become severe enough for the athletic trainers to seek help from a mental health professional.
\end{abstract}

Keywords: Patient Education; Emotional Wellness; Mental Health

\section{Introduction}

The labrum of the hip is a fibrocartilaginous structure that lies in the acetabulofemoral joint, between the femoral head and the acetabulum. With the main role of stabilizing the joint, the labrum also makes sure that the pressure that is placed upon the joint is dispersed throughout the entirety of the surface, provides the joint with adequate amounts of synovial fluid, and protects the joint against trauma by not allowing the bones or cartilage to rub directly upon each other. Research has shown that the labrum reduces $92 \%$ of the stress that is placed upon the acetabulofemoral joint [1]. In active individuals, the acetabular head is kept within the joint by the surrounding muscles and the help of the labrum. Some researchers believe that the labrum does not have a job in the function of the hip when weight is placed upon it [1].

Diagnosing an acetabular labral tear (ALT) can be challenging and the clinician must rely on the patient's signs, symptoms and special tests used during the initial evaluation. The common chief complaint of an ALT is pain present in the groin or hip flexor region.
It has also been reported, that the patient complains of pain in the posterior portion of their hip, but this is rare. Other symptoms that may be noted by the patient include, clicking within the joint, feeling like the hip is going to give out or get stuck in a certain position limiting range of motion [2]. The patient in this case study had pain in the anterior and posterior aspects of her hip but it was not constant. The patient reported that other than not stretching well enough the night before, she could not find any pattern of when the pain occurred. None of the other common symptoms associated with ALT were reported by the patient. Two special tissue tests have been found to have the least deviation in identifying this pathology. The first is the hip compression test and the second is the hip distraction test [2]. Both of these tests were performed on the patient in two different instances by the athletic trainers, and a third by the team physician and were deemed negative each time. Thus, reveals the uniqueness of this case as the patient did not have the common evaluative results of an ALT. 


\section{Patient Information}

\section{Patient}

The patient was a month past her 21st birthday upon initial evaluation. The patient is five-foot-ten-inches tall and considered to be in good health by her primary physician. She was in the preseason of her second year of collegiate sand volleyball when she began to have pain in her hip. A history of lumbar back pain had brought her into the athletic training clinic 5-weeks prior to the current evaluation. She had finished 3-weeks of rehabilitation, after returning to full strength and being able to perform at her pre-injury endurance and skill level. The patient said that she was satisfied with the treatment she had received for her back pain. She expressed that she planned to continue stretching the musculature in her back and performing abdominal and core strengthening activities on her own, after the completion of treatment, to ensure that the pain did not return. The patient had been participating fully at practice for two weeks after the conclusion of rehabilitation and before the current visit. In this interim she reported to be feeling great with mild pain in her hip and back when she did not stretch well enough following practice the night before. The patient has a history of left hip pain. In December of 2019, she was evaluated by her physical therapist, who is also a family friend, for her persistent hip pain. The physical therapist diagnosed her with a sprain of her sartorious muscle and developed a rehabilitation program for her. The patient reported that this included the following exercises, four-way hip strengthening, hip flexion against an exercise ball, and mini-squats progressing to full squats. All of these exercises appeared to have the common goal of strengthening the hip. The patient reported that this rehabilitation program had helped reduce the pain, which is why she had not mentioned it when she was undergoing an evaluation for her back pain in the university's athletic training clinic. Unfortunately, the patient's pain had returned once again. The patient confessed that she had stopped doing her rehabilitation exercises for her hip 1.5-weeks before the pain returned because she only had enough time for her back stretches and core strengthening, due to her class schedule and volleyball. The patient did not have any concerns in her family health history. She presented with a valgus deformity in her knees. It was also noted by the athletic trainers that the patient had a natural hip drop in her gate.

\section{Differential diagnosis and evaluation}

An evaluation was performed by the athletic training staff at the university. The patient's active range of motion of both hip joints were assessed as within normal limits (WNL) in flexion, extension, abduction, and adduction. The patient said that she did not have any pain during the movements but that her left hip felt tighter than the right side during all the movements. The patient's strength was also recorded as 5/5 in hip adduction, abduction, flexion, and extension. The only complaint from the patient was that she believed that her left hip was mildly weaker that her right. The athletic trainer preformed the following special tests and recorded the findings as, Ober's was negative with reported tightness by the patient and palpable tightness by the clinician along the iliotibial band, the patient did not have a leg length discrepancy, hip scouring was negative, compression was negative, and distraction was negative as well. The initial assessment of injury was that the patient had iliotibial band tightness with concern of an acetabular labral tear. The special tests were negative of a labral tear and the patient did not have a specific mechanism of injury but did say that she felt a pain deep in her joint on occasion. At this time, the assessment by the athletic trainers was iliotibial band tightness in which was the base of the treatment plan. The main goal of treatment, identified by the athletic trainers and the patient, was to decrease the patient's post practice pain within the next 3-weeks. The patient was asked to come into the athletic training clinic at least 3 times a week to perform rehabilitation in order to strengthen the musculature of her hip.

The patient believed that her left hip was tighter than the right and accepted the diagnosis of a tight iliotibial band. The patient pushed the fact that she might have a labral tear in her hip to the side, because she said that she did not have time for a major injury that required surgery because she was not willing to sit out of participation in the sport in order to recover. The patient stated that she was willing to be compliant with treatment in the athletic training room in order to loosen and strengthen the musculature of her hip. The patient fully believed that the treatment would cease the pain as it did in with the pain she had experienced in her back before treatment in the same athletic training clinic.

\section{Body structures and function}

The main evaluation evolved around the patient's hips. The large bone of the hip, also referred to as the pelvic girdle, is made of a pubis, ilium, and ischium present bilaterally. The two sides are connected anteriorly by the pubic symphysis, and posteriorly by the sacrum. The sacrum is made of the last four vertebrae of the spine which are fused. Distal to the sacrum is the coccyx, which is more well known as the tailbone. The acetabulofemoral joint is a ball-and-socket-joint. The head of the femur, which is a convex bone, sits within the concave structure of the pelvis, a region called the acetabulum. Articular cartilage, as well as the labrum sits in between the two bones in order to keep them from rubbing on each other upon movement. There are also numerous ligaments that help to hold the two structures in place, such as the transverse acetabular ligament, pubofemoral ligament, and ischiofemoral ligament. Musculature also plays a vital part in the stabilization and movement of the hip. The gluteus medius, gluteus maximus, and gluteus minimum all are base structures in the stabilization of the hip. They also help move the upper leg through abduction, external rotation, and extension. The quadriceps aid in the large motions of the hip. This includes the rectus femoris, vastus lateralis, vastus intermedius, and vastus medialis. The quadriceps, all work together to move the hip into flexion along with the hip flexors, illiacus, psoas, and sartorius. Another key component of the hip includes the biceps femoris, semimembranosus, and semitendinosus. These are the muscles that extend the hip. The last major mover of the hip 
is the iliotibial band. This runs from the superior iliac crest down to Gordy's Tubercle. This structure moves the hip into abduction and is commonly associated with tightness and pain due to rubbing on the greater trochanter or the lateral epicondyle of the tibia.

\section{Activity and participation}

The pain that the patient experienced due to the pathology only affected her in the evenings after practice. Initially, the patient's chief complaint was the pain that she experienced after practice. She said that she would be fine all day and be able to complete any activities she wished in their entirety without any restrictions due to pain, until she participated in practice. The patient reported that during practice, she was able complete all the tasks that she wished at her highest level. She reported that the moment she stopped playing the pain in her left hip engulfed her. This was when she started limping and did not have the desire to do any activities that included walking or bearing weight on her leg. On days when she participated in day-long tournaments, she said that she was able to push through the pain all day and perform at the level she deems as her highest. On the bus ride home however, she described a tightening sensation in her hip along with soreness and pain when she tried to stand up. This resolved itself by the next morning.

The patient expressed to the athletic training staff that she feels that her adrenaline keeps her from experiencing the pain when she is playing volleyball. The patient says that the minute she sits down or allows her body to cool off after participation then she immediately feels the pain. The pain occurs when the patient tries to perform other physical activities after playing volleyball, like walking, standing, and going up and down stairs. This is why the patient believes that she is able to focus on volleyball and get her adrenaline up in order to ignore the pain. This represents the patient's great desire and drive to be able to participate in this sport as she is able to ignore pain during the participation that is debilitating to her when trying to perform activities of daily living. The patient showed a frustration with this cycle of pain. She reported that she stretched multiple times a day, has tried taking pain medication, and even icing her hip at the conclusion of practice. The patient said that the pain is not a large issue because it does not affect her ability to play volleyball, but more so of an annoyance because she is not able to participate in all of the activates, she wishes to after practice.

\section{Environmental and personal factors}

When the athletic training staff questioned the patient about what activates were affected by the pain she listed, walking, going up stairs, when she wanted to make dinner after practice she would have to suffer through the pain to stand and walk in the kitchen, getting into bed was also a struggle. The athletic trainers asked the patient how much she believed the pain affected her quality of life. The patient responded saying that she could get through the majority of her day as well as practice without pain. She said that the pain was an inconvenience in the evening but did not reduce her quality of life greatly because she could still play volleyball. The athletic trainers wrapped the patient with an ice bag after every practice which she said helped dull the pain for about an hour. She believed that the ice bag and wrap was debilitating because it was difficult to walk with the ice bag and showed everyone on campus that she was injured. The patient also said that she had to go and sit in her dorm and let the ice numb her pain before she was able to do anything else somewhat pain free the remainder of the night.

The psychosocial aspect played a vital part in this case. After the patient learned that she might have a tear in her labrum she reported having depressive symptoms. The athletic trainers recorded that the patient felt an increased difficulty getting out of bed in the morning and minimal to no reason to continue through the day. This was due to the fact that the patient believed that life revolved around volleyball. The athletic trainer had to try and help the patient weigh the factors of how the pain was influencing her activities of daily living versus how important volleyball was to her. The patient's roommates and closest friends all participated in volleyball and so she stressed that she would feel left out if she was not playing. This was stressed through the patient's worry of not having anyone to hang-out with on weekends the team traveled out of town. Her concerns also revolved around her daily life and what she would do when the team was practicing and she was not able to participate due to the tear in her labrum. The patient also had been falling in love with this sport for as long as she could remember and expressed that she would be lost without it. The athletic trainer then asked her to recall her pain. Did she want to be able to function for the entire day, make dinner for herself and possible family, play with her future children? The patient went home that night and came back to the clinic the following week with a completely different outlook. She said that she would do rehabilitation in hopes that it would help reduce the pain that she felt post-practice. The patient did acknowledge the fact that she did not want to deal with this pain for the rest of her life, but she stressed that her main goal was to continue to play volleyball and hopefully be able to reduce her post-practice pain.

The patient lived on campus and had a five- minute walk to get to the athletic training clinic from her dorm room. The patient reported that a few minutes were added to the walk when she had the ice bag wrapped onto her hip after practice. The patient expressed that the longest time she ever spent walking to get to the athletic training facility was seven-minutes. No pain was ever noted by the patient when she was walking on campus before practice or on days, she did not have practice. The athletic trainers were available for treatment two hours prior to the start of beach volleyball practice and two hours after practice. The athletic trainers remained in the athletic training clinic during practice. The beach volleyball coach and entire team had contact information for their specified athletic trainer's office and cell phone number. All participants were encouraged to contact the athletic trainer or report to the athletic training clinic if a problem arose during practice. The beach volleyball facility was a five-minute walk from the athletic training clinic.

The patient was covered under the universities secondary health insurance for the entire time she was an eligible athlete 
under their care. If the patient had decided to undergo surgery during her time as an athlete at the current university, she would not have been responsible for any of the medical expenses. This decision was made based on the assumption that the ALT occurred during the patient's participation in beach volleyball. The patient's primary insurance would initially be billed for the cost of all medical care and then the university's secondary insurance would cover the rest of the expense.

\section{Interventions}

A daily pattern was noted by the athletic training staff, when the patient came in to complete her rehabilitation program. The athletic trainers implemented a plan of care in which the patient was asked to come into the athletic training room at least 3 times a week to participate in. At the beginning of each session, the athletic trainers asked the patient to rate her pain on a 10-point pain scale. The patient's typical answer was a score of 1 . The highest score that the patient rated her pre-rehabilitation pain at over the course of the treatment was a 3 . The athletic trainers also noted that the patient walked with a normal gate pattern before every treatment session. The patient warmed-up on the bike for 10-minutes and then applied heat to her left hip, for as long as she felt she needed to warm-up the area. This routine was carried-out by the patient in the preparatory stages of every rehabilitation session. No pain was ever experienced by the patient when spinning on the stationary bike. The patient did express that when she first started to pedal the muscles in her hip felt tight but as she continued through the 10-minutes they felt like they were beginning to loosen up. The patient reported that the heat helped relax the muscles of her hip. The patient was then given the following exercises, by the athletic training staff, that focused on strengthening her hip; four-way hip (3 sets of 10 repetitions), monster walks (3 sets of 30 yard laps (down 15 yards and back 15 yards=1 lap), and clams ( 3 sets of 10 repetitions). The patient preferred to perform the four-way hip and clam exercises bilaterally and was encouraged by the athletic training staff to do so. The patient said that her left hip just felt tighter than her right one during the exercises and that she did not have the entire range of motion in the left hip compared to the right. The patient then rolled out on a foam roller until she felt that the muscles in her hip were loosened. The patient also stretched her hip flexors, hamstrings, quadriceps, hip abductors, hip adductors, and gluteals all bilaterally for the time that she deemed adequate to loosen them all. After reporting that she thought that the tightness in the musculature of her left hip had been reduced, the patient was sent to practice. The athletic training staff asked the patient to come back to the athletic training clinic after she showered following the conclusion of practice. When the patient sought out the athletic trainers post-practice the patient presented with an antalgic gate. She reported a sharp shooting pain through her left hip joint. The patient mean rating of the pain as a 7 on the 10-point pain scale. The pain was never reported lower than 6.5 or higher than an eight. She was given ice that was wrapped onto her hip by the athletic training staff. The patient reported that the ice gave her relief for about an hour after it was removed. She also took 400-milligrams of Ibuprofen when the pain got unbearable. The patient rated unbearable as above an 8 on the 10-point scale. This occurred two to three times a week at various times after practice. The patient said that she was relieved from the pain for the rest of the night after taking the dose of the non-steroidal anti-inflammatory drug. The patient did not see any improvement in pain after 3 weeks of treatment and felt like she was in a continues cycle of pain. At this time, the patient was referred by the athletic trainers to the team physician. At no time during the current treatment for the patient's hip did she ever report the pain in her back returning.

\section{Outcomes}

\section{Body structure and function}

The patient was not having improvement in pain and saw the team physician after 3-weeks of rehabilitation. The physician evaluated active range of motion as within normal limits after checking hip flexion, extension, abduction, adduction, internal rotation, and external rotation. The physician also found the patient's hip strength to be WNL. This was determined through hip flexion (5/5), extension (5/5), abduction (5/5), adduction (5/5), internal rotation (5/5), and external rotation (5/5) without the patient experiencing pain. The major finding of the physician was during the special tests portion of his examination, in which he felt a popping during the hip scouring and recorded a positive finding. The patient said that she did not feel this popping sensation, nor did it cause her any pain. It was also noted by the physician that the patient had a negative Ober's, negative FABER, negative compression, and negative distraction tests. The physician had concern of a labral tear and ordered a magnetic resonance arthrogram (MRA) which was performed later that week. The finding of a labral tear was confirmed early the following week and the patient was devastated. When the patient initially received the diagnosis, she said that there was absolutely no way that she was going to have surgery. The outlook of having pain for the rest of her life upset the patient but she was not willing to give up volleyball at that time.

\section{Activity and participation}

The patient was given three plans of action that were outlined to her by the athletic trainer. The first being that the patient could undergo the operation to fix the torn labrum right now by the team physician and miss the rest of the 2019 beach volleyball season. Second, was that the patient could not have surgery at all and continue rehabilitation and pain modulating treatments in order to get mild short-lived relief for the rest of her two years as a collegiate volleyball player, and then reconsider the operation. The final option that the patient was given, was to continue to play this season while receiving treatment through modalities for pain and rehabilitation for strength and have the procedure to fix the labral tear over the summer of 2019. This would allow her enough time to go through rehabilitation and slowly return to play at the beginning of the 2020 beach volleyball season. The patient's initial choice was no surgery at all, thus ruling out the first option due to the fact that she was unwilling to stop playing volleyball. The patient did not 
like the third option because she wanted to be able to participate in summer activities like going to the pool and wearing shorts and did not want to be limited by the incisions or a brace that would be included in the surgical treatment plan. The patient was undecided about the second plan of treatment but was not a huge proponent because she did not want to have surgery right after she graduated from college. The following week, the patient had rethought her original decision. She had recalled the previous conversation, with the athletic training staff, about life after her collegiate volleyball career and decided to have the operation proceeding her eligibility as a collegiate athlete.

The athletic training staff clearly iterated to the patient that if she had the operation when she was still an active athlete at the university the cost of her medical care would be covered through her primary insurance and the university's secondary insurance. Once her eligibility was expired she would not be covered by the university's secondary insurance and the cost would be her responsibility. The patient did not let this information change her decision and believed that the cost of surgery was far less than the cost of not being able to participate in beach volleyball.

The patient agreed to stay in communication with the athletic trainers throughout her time as a collegiate athlete at the current university. She agreed to report to the athletic training clinic at least 3 times a week for treatment. The patient worked with the athletic trainers to develop a treatment goal of pain modulation and strengthening of the musculature of her left hip. The patient's pain will be monitored using the 10 -point pain scale which will be taken by the athletic trainers, and recorded, at the beginning of each rehabilitation session. The treatment that the patient will receive that day will be based off of her perception of pain. Modalities will be used to reduce pain, if needed. These will include interferential current electrical stimulation and heat based on the preference of the patient. The patient had already reported during the previous 3-weeks of visits to the athletic training clinic that she felt that heating her left hip was very beneficial because the hip felt looser after the treatment. Therefore, the athletic trainers made it a priority to include this in the patient's pre-rehabilitation plan. If the pain is well regulated the patient will continue to do rehabilitation exercises to strengthen and stretch the musculature of her hips, bilaterally. These exercises would include the ones she already had been performing, adding additional resistance, as well as fire-hydrants (starting at 3 sets of 10 repetitions), bird-dogs (starting at 3 sets of 10 repetitions), and flexion against an exercise ball while leaning upon a wall (starting at 3 sets of 10 repetitions), and additional abdominal and core strengthening activities as pain allowed. Repetitions and sets that the patient performs were to be increased or decreased based on the mutual consensus between the athletic trainers and the patient that day. During the 3-weeks of treatment that the patient had already completed, she believed that stretching and foam rolling the muscles acting upon her hips after completing the rehabilitation exercises, exponentially helped loosen the muscles. Therefore, the athletic trainers ensured that the patient always had enough time between rehabilitation and practice to be able to stretch and foam roll.

\section{Environmental and personal factors}

After the diagnosis of a labral tear the patient contracted a cold that kept her in bed that weekend. She reported to the athletic training clinic the following Monday with an outlook that life was over because she was not able to play volleyball for three days due to the severity of the symptoms of the cold. In general, the patient was dwelling on the fact that she had an injured hip. The athletic trainers helped the patient weigh the factors of taking that day off of practice and resting or possibly being sick longer. The patient saw the need for rest and that everything was going to be alright if she took one day off and went back to her dorm to sleep instead of participating in practice. The patient reported again the next day to the athletic training clinic, with the outlook of getting stronger through rehabilitation. The patient expressed that the symptoms from her cold had subsided, and were nearly gone. This episode again stressed the great value and high role that the sport of volleyball played in the patient's life.

The importance of beach volleyball was a large motivating factor in the patient's adherence to rehabilitation. She continued to come into the athletic training clinic at least 3 times a week for treatment even though the pain was not improving for the initial 3-weeks. Even during the patient's first depressive spell she came into the athletic training clinic seeking treatment so that she was able to practice that afternoon. The patient reported stretching at least three times every day on her own to try and keep her hip as loose as possible. The patient said that she could care less whether or not she had pain walking from class to class but only stretched in order to ensure that her muscles were loose enough to perform her best at practice that afternoon. This patient was very motivated and did everything that the athletic trainers asked of her because her one goal was to be able to play volleyball without having postactivity pain. The patient's abidance to rehabilitation may go back to the fact that the athletic trainer told her after the initial evaluation that if she came into the athletic training clinic and worked hard at the exercises that the athletic training staff gave her, she could continue to practice as pain allowed. The other option that the athletic trainer stressed was that if the patient did not come into the athletic training clinic to do her rehabilitation the patient would not be able to practice due to the fact that a decrease in strength could possibly cause the labrum to tear further or other structures of her hip and possibly back to become injured.

\section{Discussion}

There are many differential diagnoses for patients with ALTs which leads to the condition being found later in the treatment a common happening, as seen in the patient presented in this study.2 Not identifying, and having the torn labrum repaired in the acute stages of injury can cause more damage to the structures of the acetabulofemoral joint. The longer the labrum is left torn the greater the chance of the patient contracting dysplasia. If the 
labrum is not fixed within five years of the initial tear the likelihood of the development of dysplasia is increased greatly [3]. ATLs can be coupled with labral erosion which allows the femoral head to rub against the acetabular bone in the area of the tear resulting in a greater wearing away of the cartilage. This was found to be true in $73 \%$ of patients [3]. This break down of the cartilage can also be a predisposing factor to arthritis. The longer the tear is left within the joint, the greater amount of time the bones are allowed to rub against each other, creating a larger deficit of cartilage and a higher likelihood of arthritic development [3]. The theme of long-term pain was presented to the athlete in the development of a plan of care. The clinician did not stress the facts of the wearing down of the structures of the joint and the greater chance of arthritis the longer the ATL is left untreated when developing a plan of care with the patient. This represents a lack of evidence-based practice. If this research had been done and the patient was informed that the longer, she waited to have the ALT surgically repaired, the greater risk she was at for developing arthritis. The cartilage within the bone that is allowed to wear down would not be able to be fixed in the labral repair surgery and still cause pain in the long-term.

With this information in place, the only option for complete pain cessation is surgical intervention. Literature mentions that a bout of rest and anti-inflammatory medications may be able to decrease the pain for a short amount of time. Rehabilitation exercises can also be added as pain allows. Ultimately, conservative intervention is becoming increasingly shorter as it has been noted that the operating room is the final destination for all ALT sufferers who are finally rid of their pain [2]. The patient in this case was given the option of holding off on surgical intervention and continuing with rehabilitation. Even though this was a practice of patientcentered care by the Athletic Trainers, the quality of life after her participation in collegiate sports will most likely be lowered the longer operational repair of the labrum is held off.

The patient showed unpretentious signs of depression during the course of treatment. One of the risk factors for depression in the athletic population is injury [4]. Even though the patient must have a negative impact and at least five of the symptoms of depression in order to have a diagnosable mental health disorder, the feelings of this patient were still addressed immediately when observed by the athletic training staff [5]. When the patient reported that it was difficult to get out of bed and that if she could not play volleyball then she did not know that to do with her life her feelings were acted upon immediately by the athletic trainers. They helped the patient see that there was much more to life than volleyball, like school, her friends and family, her future career. It took a few days for the idea to sink in the patient began to accept her injury and decided the only thing that she could do was to work hard at the rehabilitation exercises that were given to her.

\section{Clinical Bottom Line}

Even though a patient at hand, may only have presented with one of the common characteristics of a certain pathology, it should remain within the differential diagnosis until ruled out. Evidencebased research should be conducted for each of the pathologies included in the differential diagnosis, in order to develop a plan based on which one will cause the greatest harm, if left untreated the longest amount of time. ALTs are an injury to the acetabulofemoral joint that will cause long term damage as time progresses from when the tear occurs to when it is surgically repaired. Due to this observation, it can be noted that surgical repair is the best care for this pathology and should be conducted as acutely as possible.

This case presented the challenge of weighing patient-centered care and evidence-based practice. The patient's one and only goal was to continue to play volleyball and try to reduce the postpractice pain she chronically experienced. When given the choice for surgical repair which is the only known treatment that will stop the pain, the patient would not accept the procedure. The patient wished to continue to play volleyball and have the surgery once her eligibility as a collegiate volleyball player had expired. The athletic trainers took this into account and developed a treatment plan with the goals of pain modulation and strengthening of the musculature of the patient's hip in order to allow her to hold off on surgical intervention until she was no longer able to participate in collegiate volleyball.

Injury is a risk factor for depression and the patient should be monitored at all times for mental illness. If any signs are observed they should be addressed immediately by the primary care provider, and if they persist the clinician should seek help from a mental health professional.

\section{Acknowledgment}

None.

\section{Conflict of interest}

No conflict of interest.

\section{References}

1. Hunt D, Clohisy J, Prather H (2007) Acetabular labral tears of the hip in women. Phys Med Rehabil Clin N Am 18(3): 497-520.

2. Groh MM, Herrera J (2009) A comprehensive review of hip labral tears. Curr Rev Musculoskelet Med 2(2): 105-117.

3. Mc Carthy J, Noble P, Aluisio FV, Schuck M, Wright J, et al. (2003) Anatomy, pathologic features, and treatment of acetabular labral tears. Clin Orthop Relat Res 406: 38-47.

4. Reardon CL, Hainline B, Aron CM, Baron D, Baum AL, et al. (2019) Mental health in elite athletes: International Olympic Committee consensus statement. Br J Sports Med 53(11): 667-699.

5. Jenkinson C, Layte R, Jenkinson D, Lawrence K, Petersen S, et al. (1997) A shorter form health survey: can the SF-12 replicate results from the SF36 in longitudinal studies? J Public Health Med 19(2): 179-186. 